is shown for both group (ii) and the maximally inhibited group (i) that (I) decompositions have all the characteristics of unimolecular reactions, and that (2) the effects of structural variations are comprehensible within the framework of present-day chemical theory. Discussion centred on the effect of surfaces, and the variations between the experimental fall-off characteristics and those predicted by Slater and Kassel theories.

The paper "The Inhibition of $n$-Butane Pyrolysis by Propylene" by Mr. C. P. Quinn and Dr. J. H. Purnell (Cambridge) was presented by the former. The kinetics of the formation of the products of the pyrolysis of $n$-butane in the presence and absence of propylene are studied by means of high-speed gas chromatography. It is shown that the product ratio $\mathrm{C}_{2} \mathrm{H}_{4}: \mathrm{C}_{2} \mathrm{H}_{6}$ is greater than unity, a function of temperature and pressure, and increases linearly with inhibitor pressure. It is concluded that this is incompatible with the hypothesis of two concurrent processes, one of which (free radical) is halted by the inhibitor and the other of which (molecular) is unaffected. It is therefore proposed that the fully inhibited reaction proceeds by a modification of the free radical chain mechanism which is responsible for the whole of the uninhibited reaction. Competition between the two reactions:

$$
\begin{gathered}
\mathrm{C}_{2} \mathrm{H}_{5}+\underset{\mathrm{C}_{2} \mathrm{H}_{5} \rightarrow \mathrm{C}_{2} \mathrm{H}_{4}+\mathrm{C}}{\mathrm{C}_{4} \mathrm{H}_{10}} \mathrm{C}_{2} \mathrm{H}_{6}+\mathrm{C}_{4} \mathrm{H}_{9} \\
\mathrm{H}_{2}
\end{gathered}
$$

is found to play an important part in both the uninhibited and the fully inhibited processes. The increase in the activation energy for $n$-butane pyrolysis at low pressures is thus explained, and the classification of paraffins on the basis of changes with pressure of the order and activation energy of the fully inhibited pyrolysis (due to Peard, Stubbs and Hinshelwood) is interpreted in terms of the classes of hydrocarbons which do and do not give the competitive reactions listed above.

The final paper on "The Effect of Surface and Nitric Oxide on the Pyrolysis of Isopentane" was given by Prof. W. A. Bryce (University of British
Columbia, Vancouver). The effect of surface : volume ratio and nitric oxide pressure on the decompositionrate and product distribution of isopentane is studied. It is shown that alteration in the surface : volume ratio alters the rate at any fixed pressure, and the rate/nitric oxide pressure curves for the inhibited reaction. The main products of pyrolysis are methane, propylene and iso-butylene; the latter is unaltered by increase in pressure of nitric oxide, whereas the other two products are increased. Ethylene and ethane are minor products and the ratio increases with nitric oxide pressure, and with decrease in surface : volume ratio. The observations are interpreted on the basis of heterogeneous initiation of the pyrolysis. It is shown that $n$-pentane and neopentane behave differently from isopentane, and that di-allyl sensitizes the rate of decomposition of $n$-pentane, presumably by the reaction:

$$
\mathrm{C}_{3} \mathrm{H}_{5}+n-\mathrm{C}_{5} \mathrm{H}_{12} \rightarrow \mathrm{C}_{3} \mathrm{H}_{6}+\mathrm{C}_{5} \mathrm{H}_{11}
$$

The discussion covered many issues and there was no general agreement on inhibition mechanisms. The following brief summary from the discussion indicates some of the important questions to which answers should be sought in any examination of the effect of inhibitors on gas phase decomposition reactions: (1) the order of the reaction in both substrate and inhibitor; (2) consumption (or otherwise) of inhibitor; (3) the nature of the reaction(s) between radical and inhibitor, and substrate and inhibitor; (4) subsequent reactions of the products of these reactions; (5) the effect of surface; (6) the effect of different inhibitors; (7) the effect of adding a second inhibitor to a maximally inhibited reaction; (8) the assumption of molecular decomposition mechanisms; (9) comparison of product analysis/time curves with pressure/time curves; (10) the effect of temperature variation on reaction possibilities.

It is hoped that this discussion, by revealing the scope of the many kinetic problems involved in an understanding of inhibition mechanisms, will lead to an advance in our understanding of a theme that can be as complex as oxidation. B. G. GowenLock

\title{
CELL DIFFERENTIATION AND INTERACTION
}

T HE annual research conference of the Biology Division, Oak Ridge National Laboratory, was held at Gatlinburg, Tennessee, during April 9-12. The subject was "Specificity of Cell Differentiation and Interaction", and a mixed gathering of bacteriologists, biochemical cytologists, embryologists, geneticists and immunologists, including a small number from Europe and Sir Macfarlane Burnet from Australia, attended.

After introductory remarks by Dr. A. Hollaender, head of the Biology Division, Oak Ridge National Laboratory, and Dr. A. Weinberg, director of the Oak Ridge National Laboratories, Dr. J. Brachet (Université Libre de Bruxelles) gave the opening talk in which he outlined results of measurements of deoxyribonucleic acid and ribonucleic acid on amphibian oocytes and embryos. New methods have confirmed that there is little or no DNA synthesis before the late blastula stage in the embryo, so that pre-existent cytoplasmic DNA evidently contributes to the nuclei during cleavage. This probability was used by Dr. J. A. Moore (Columbia University, New York), the second speaker, to explain the results of interspecific nuclear transfers in amphibian embryos that he reviewed, in which the nuclei seem to undergo more or less permanent genetic change after dividing a few times in foreign cytoplasm. In discussion, Dr. R. W. Briggs (Indiana University) mentioned that chromosomal translocations have been detected in diploid nuclei after transplantations of this kind. Brachet described nuclei with various staining peculiarities, suggestive of abnormal DNA and RNA content, that arise in some lethal hybrid embryos. He also mentioned new work on Acetabularia, including indications that some low-molecular forms of DNA may be synthesized in the cytoplasm in the absence of the nucleus.

Cell-interaction during embryonic differentiation was discussed from various angles by Drs. T. Yamada (Oak Ridge), C. Grobstein (Stanford University) and A. A. Moscona (University of Chicago). Dr. Yamada had achieved the conversion of explanted amphibian 
gastrula ectoderm into mesoderm, after contact for $3 \mathrm{hr}$. with a protein fraction from guinea-pig bone marrow. He was studying the mechanism of this conversion, and also of the regeneration of lens from iris cells, by autoradiography, fluorescent antibody techniques and electron microscopy. Dr. Grobstein pleaded for a distinction between 'heterotypic' and 'homotypic' control of cell differentiation, to interpret the dependence of pancreatic epithelium not only on the presence of mesenchyme but also on integrity of reasonably large epithelial pieces, for good differentiation of acini. Dr. Moscona, describing the ability of mixed cultures of dissociated mouse and chick tissues to form composite organs whereas cells of different tissue types from the same animal do not combine, pointed out that after an initial nonselective phase of reaggregation the cells sort out into distinct tissue types by a process which he believes may depend on a molecular fit between protein and carbohydrato at the cell surfaces. The problem he raised of how embryonic cells recognize each other needs linking up with theories about the development of immune mechanisms in embryos, but in an evening round-table discussion on this topic the cellular embryologists failed to get to grips with the immunologists. Immunologists who spoke at the conference were Dr. T. Makinodan (Oak Ridge), who emphasized the importance of plasmacell differentiation during immuno responso, and Dr. G. Möller (Karolinska Institutet), who described brilliantly the use of tumour-cell strains to study tissue antigenicity and pointed out discrepancies that had arisen in dating the earliest appearance of transplantation antigens in developing animals by different methods. Dr. R. E. Billingham (The Wistar Institute, Philadelphia) brought together genetical and immunological considerations in reviewing the different abilities of bone marrow and lymph-node tissues to induce tolerance of skin grafts, when different strain crosses of rats and mice were used.

Anothor aspect of cell differentiation was dealt with by Prof. C. H. Waddington (University of Edinburgh), who showed electron micrographs of developing amphibian notochord cells, and of ommatidia of normal and eye-mutant strains of Drosophila. $\mathrm{He}$ also showed a film illustrating the different behaviour of myoblast and neural cells in culture, even before they are structurally distinguishable. Any theory of differentiation controlled by genes has to account for the regional differentiation within cells that is now visible in electron micrographs, as well as how such differences are established when the cell-contents are in constant commotion as the ciné pictures show.

In his final summary of the conference, Sir Macfarlane Burnet (The Walter and Eliza Hall Institute of Medical Research, Melbourne) reiterated that genetic information must control all types of differentiation, and he called for an intensified study of gene-controlled immunological anomalies, such as human a-gammaglobulinæmia. Ho also pointed out our complete ignorance of whether systemic immune mechanisms exist in invertebrates, which do not appear to possess gamma-globulins.

Other speakers at the conference were Drs. L. Herzenberg (Stanford University) and A. J. Riker (University of Wisconsin), who described differentiation in cultures of mouse lymphoma, and gall-infected plant tissues, respectively, and Dr. V. Hamburger (Washington University, St. Louis), who reviewed evidence for cell-specificity in the development of the nervous system. The full proceedings, including discussions, will be published as a supplement to the Journal of Cellular and Comparative Physiology later this year.
E. M. DeUChaR

\section{GRAZING IN TERRESTRIAL, FRESHWATER AND MARINE ENVIRONMENTS}

T WE fourth symposium to be arranged by the British Ecological Society was held at the University College of North Wales, Bangor, during April 11-14. The subject was treated in the broadest sense, and included not only pasture and range grazing by terrestrial herbivores but also planktonic grazing and other grazing-like phenomena of freshwater and marine environments.

In the first contribution to the symposium, $\mathrm{Mr}$. A. Macfadyen, Zoology Department, University of Swansea, classified the main routes through which matter and energy can flow in a model ecosystem, and discussed the magnitudes of the main trophic components in several contrasting systems, including grassland and plankton. The relationship between stock and productivity can vary ovor several orders of magnitude, according to the biology of the organisms concerned. Thus the standing crop of plant matorial in the marine environment is very small compared with that in terrestrial environments, although the onergy-flow is of similar magnitude. Grazing yields can be reduced by energy-flow into unproductive pathways, such as ungrazed organic matter by plants, and inefficient utilization of plant material by herbivores. It is therefore clearly important to have a framework within which to compare present performances of ccosystems with potential yields.

Mr. M. B. Alcock, Department of Agriculture, University College of North Wales, Bangor, discussed the problem of achieving maximum output of animal products from grassland. The responses of the plant to defoliation may be due to changes in root growth and uptake of minerals, to utilization of carbohydrate reserves, or to changes in the interception of light energy.

Dr. J. D. Ovington, Nature Conservancy, St. Tves, Huntingdonshire, described work carried out at the University of Minnesota in which he compared the productivity of prairie, savanna and oakwood. The presence of woody plants greatly increases the nutrient circulation and utilization of the site, with the result that the primary productivity of the oakwood almost reaches that of intensively managed fields of maize nearby.

Prof. L. B. Slobodkin, University of Michigan, discussed grazing phenomena in fresh-water, and emphasized that the limited extent and uniformity of most freshwater environments leads to unstable rolationships between planktonic species and, in consequence, to wide fluctuations in population numbers. 